\title{
Recurrent Parotitis: Extrapulmonary Manifestation of Childhood Tuberculosis
}

\author{
Keya Lahiri, Fehmida Najmuddin*, Rajesh Rai, Imran Patel, Kapil Shukla, Khushal Avasthi \\ Department of Pediatrics, D Y Patil Medical College, Hospital \& Research Centre, Navi Mumbai, India \\ Email: "fehmidanc@hotmail.com
}

Received 11 September 2015; accepted 7 November 2015; published 11 November 2015

Copyright (C) 2015 by authors and Scientific Research Publishing Inc.

This work is licensed under the Creative Commons Attribution International License (CC BY).

http://creativecommons.org/licenses/by/4.0/

c) (i) Open Access

\begin{abstract}
Recurrent parotitis of childhood is a rare condition involving the largest salivary gland. The aetiology is multi-factorial and is usually non-obstructive or non-suppurative type of inflammation. It involves recurrent swelling of the parotid gland unilaterally or bilaterally over a period of months to years. Tuberculosis rarely involves the parotid gland, however in developing countries where tuberculosis prevalence is very high, any child with recurrent parotitis should be investigated for the same. We hereby, describe a 2 and half-year-old female child with recurrent parotid gland swelling below the right ear since 6 months. The swelling was acute in onset, gradually increasing in size with no discharge or pain. There was no history of fever, cough, cold, dryness of mouth or eyes, joint pain or rashes. There was history of koch's contact in the maternal grandfather. A positive mantoux test and significant cervical lymphandenaopathy on Computed Tomography scan was noted. Common causes of recurrent parotitis, i.e. sjogrens syndrome, immunodeficiency and obstruction were ruled out. On the basis of the above history and investigations, the child was diagnosed as tuberculous parotitis.
\end{abstract}

\section{Keywords}

Parotitis, Recurrent, Tuberculosis, Pediatrics

\section{Introduction}

Mycobacterium tuberculosis involving the parotid gland as an extra-pulmonary site is extremely rare. Affection of the parotid gland is uncommon in a developing country like India, where the incidence of tuberculosis has been increasing over the past decades [1]. The inhibitory effect of saliva on mycobacterium tuberculosis protects the gland from being commonly infected. Cases of tubercular parotitis are usually seen in adult population, unlike paediatrics where only few have been reported so far [2]. Amongst the infectious agents, the commonest

*Corresponding author.

How to cite this paper: Lahiri, K., Najmuddin, F., Rai, R., Patel, I., Shukla, K. and Avasthi, K. (2015) Recurrent Parotitis: Extrapulmonary Manifestation of Childhood Tuberculosis. Journal of Tuberculosis Research, 3, 122-125.

http://dx.doi.org/10.4236/jtr.2015.34018 
organism causing suppurative parotitis is Staphylococcus aureus. The diagnosis of tuberculous parotitis (TP) could pose a challenge to the practising physician, as the typical systemic symptoms are often absent [3]. Unilateral TP is often misdiagnosed as a benign parotid tumor.

\section{Case Report}

A 2 1/2-year-old female child born of non-consanguineous marriage, hailing from Pune, India, presented to a tertiary care hospital with complaints of recurrent swelling below the right ear since 6 months. The swelling was acute in onset, gradually increasing in size with no discharge or pain and would slightly decrease after analgesics and oral antibiotics. The swelling would reduce and reappear after repeated antibiotics usage. There was no history of fever, cough, cold, dryness of mouth or eyes, joint pain and rashes. There was no associated complaints of difficulty in chewing, drooling of saliva or deviation of the angle of the mouth.

There was history of koch's contact in the maternal grandfather, who was on therapy for pulmonary tuberculosis. The child belonged to a lower middle class, was immunized for age and developmentally normal

Child was conscious, co-operative, averagely build and nourished with heart rate of 102 beats/min, respiratory rate of 26/min, temperature of $98{ }^{\circ} \mathrm{F}$ with blood pressure of 90/56 mm of $\mathrm{Hg}$. Anthropometric measurements were normal for her age. There was pallor, with cervical lymphadenopathy with largest measuring $1.5 \mathrm{~cm} \times 1.5$ $\mathrm{cm}$. On local examination, there was a right parotid swelling $3.5 \mathrm{~cm} \times 3.5 \mathrm{~cm}$, extending from pre auricular to post auricular, firm in consistency, rough surface with diffuse margins (Figure $1^{1}$ ) The swelling had no signs of inflammation and there were no other stigmata of tuberculosis. The Stenson's duct opening, facial nerve and systemic examination were normal.

Hemoglobin was $9.5 \mathrm{gm} / \mathrm{dl}$, Total leucocyte count was 16,300/cmm with neutrophils of $47 \%$, lymphocytes $45 \%$ and platelets-503,000/cmm.

Other investigations include: (Table 1).

\begin{tabular}{|c|c|}
\hline Investigations & Results \\
\hline ESR & $15 \mathrm{~mm} / \mathrm{hr}$ \\
\hline Sr. IgG & $2077 \mathrm{mg} / \mathrm{dl}(340$ - 1200) \\
\hline Sr. Amylase & $64.8 \mathrm{U} / \mathrm{L}(50$ - $100 \mathrm{U} / \mathrm{L})$ \\
\hline ANA & Normal \\
\hline ANTI-RO/ANTI-LA & Negative \\
\hline HIV & Non-reactive \\
\hline RA Factor & Normal (10.00 IU/ml) \\
\hline
\end{tabular}

A positive mantoux test $12 \times 12 \mathrm{~mm}$ was noted. Chest $\mathrm{X}$ ray and Computed tomography (CT) were normal. The Schirmer's tear test was negative. Gastric lavage for acid fast bacilli was negative.

Sialogram evaluation was normal and ultrasonography revealed enlarged right parotid gland with bilateral cervical multiple discrete lymph nodes. Computed Tomography of the neck was suggestive of bulky right parotid gland showing heterogenous contrast enhancement with multiple enlarged bilateral lymphodes. Fine needle aspiration (FNAC) of the gland revealed moderately cellular smears with few ductal acinar cells \& plenty of lymphocytes.

The diagnosis of tuberculous parotitis was based on koch's contact, positive mantoux test with significant cervical lymphandenopathy. The other common causes of recurrent parotitis viz obstruction, immunodeficiency and sjogrens syndrome were ruled out. The child was initiated on 9 months of anti-tubercular [2 (HRZE) +7 (HR)] therapy.

\section{Discussion}

The typical onset of recurrent parotitis is between 3 to 6 years of age and is characterized by fever, malaise and

\footnotetext{
${ }^{1}$ Note: Figure 1 and Figure 2 are of the patient. After obtaining a written consent from the patient's parents, the authors clicked the above pictures pre and post therapy.
} 


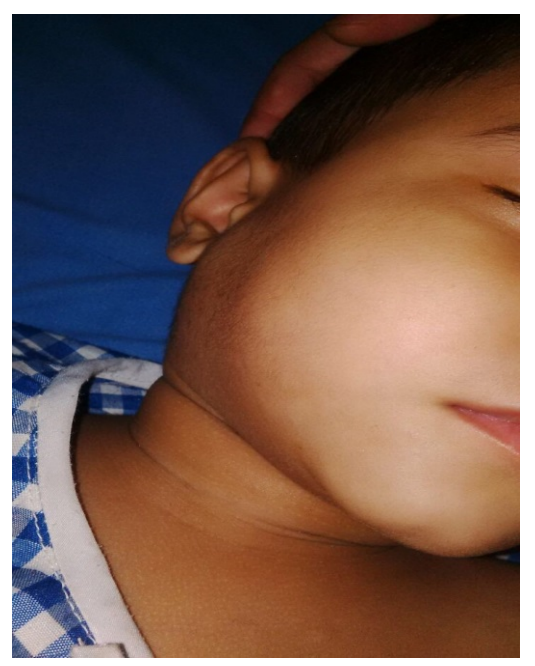

Figure 1. Parotid swelling.

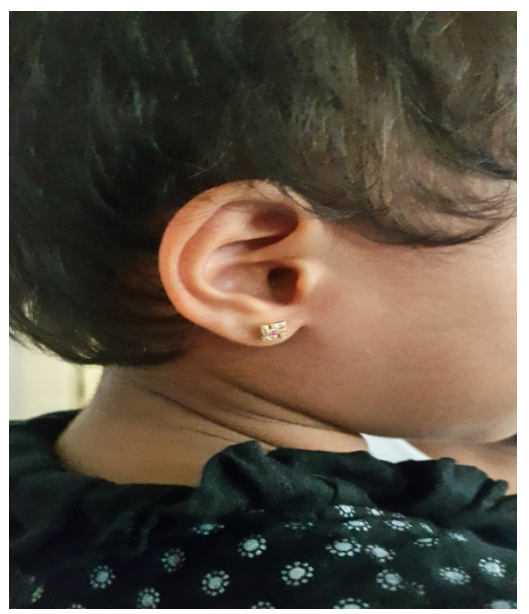

Figure 2. Patient post therapy.

pain during mastication and swallowing. However our case presented as a non-tender, recurrent swelling without any associated complications. It is usually a self-limiting condition requiring conservative management with varied duration of improvement [4].

Two forms of tubercular parotitis have been described namely the localized one which involves the intraglandular or periglandular lymphnodes and the diffuse form which affects the whole gland [5].

It is usually a slow growing, non-tender swelling which involves the anterior and inferior areas around the ear. The spread of mycobacterial infection within the oral cavity is via the salivary duct into the salivary gland or passage into the neighbouring lymphnodes via lymphatic drainage. It can also spread via hematogenous or lymphatic route from a pulmonary foci [6].

The difficulties in the diagnosis of TP are the modalities which have limitations and lack specificity [7]. FNAC has a sensitivity of $81 \%-100 \%$ and specificity of $94 \%-100 \%$ [8], but was inconclusive in our case.

Surgical exploration could lead to permanent facial nerve damage, gland destruction, fistula formation [9] and was deferred due to the negative consent given by the parents.

The child has been gaining weight, with no further episodes of parotid swelling post anti-tubercular therapy on follow-up (Figure $2^{1}$ ).

\section{Conclusion}

In conclusion, tubercular parotitis should be considered as a major differential diagnosis in a child presenting 
with recurrent parotitis in India. In future, the authors strongly suggest a thorough tuberculosis work-up in pediatric age group with either unilateral or bilateral recurrent parotid gland swelling.

\section{References}

[1] Tauro, L.F., George, C., Kamath, A., Swethadri, G. and Gatty, R. (2011) Primary Tuberculosis of Submandibular Salivary Gland. Journal of Global Infectious Diseases, 3, 82-85. http://dx.doi.org/10.4103/0974-777X.77301

[2] Sarangi, et al. (2015) Clinical Case Study of Tuberculosis in Parotid Gland Found in Children at a Medical School in South East Asia. Asian Journal of Pharmaceutical and Clinical Research, 8, 3-5.

[3] Birkent, H., Karahatay, S., Akcam, T., Durmaz, A. and Ongoru, O. (2008) Primary Parotid Tuberculosis Mimicking Parotid Neoplasm: A Case Report. Journal of Medical Case Reports, 2, 62. http://dx.doi.org/10.1186/1752-1947-2-62

[4] Leerdam, C.M., Martin, H.C. and Isaacs, D. (2005) Recurrent Parotitis of Childhood. Journal of Paediatrics and Child Health, 41, 631-634. http://dx.doi.org/10.1111/j.1440-1754.2005.00773.x

[5] Handa, U., Kumar, S., Punia, R.S., Mohan, H., Abrol, R. and Saini, V. (2001) Tuberculous Parotitis: A Series of Five Cases Diagnosed on Fine Needle Aspiration Cytology. The Journal of Laryngology \& Otology, 115, 235-237. http://dx.doi.org/10.1258/0022215011907073

[6] Myer, C. and Cotton, R.T. (1986) Salivary Gland Disease in Children: A Review-Part 1. Acquired Non-Neoplastic Disease. Clinical Pediatrics, 25, 314-323. http://dx.doi.org/10.1177/000992288602500607

[7] Kontopoulou, T., Fanourgiakis, P., Samarkos, M., Mintzias, D., Peppas, C., Rontogianni, D.D. and Vaidakis, E. (2004) Tuberculosis of the Parotid Gland: Case Report and Literature Review. Médecine et Maladies Infectieuses, 34, 488-490. http://dx.doi.org/10.1016/S0399-077X(04)00178-7

[8] Iseri, M., Aydyner, O., Celik, I. and Peker, O. (2005) Tuberculosis of the Parotid Gland. The Journal of Laryngology \& Otology, 119, 311-313. http://dx.doi.org/10.1258/0022215054020494

[9] Singh, B.S. and Maharaj, T.J. (1992) Tuberculosis of the Parotid Gland: Clinically Indistinguishable from a Neoplasm. The Journal of Laryngology \& Otology, 106, 929-931. http://dx.doi.org/10.1017/S0022215100121310 